\title{
Haemodialysis acutely reduces the plasma levels of ADMA without reversing impaired NO-dependent vasodilation
}

\author{
Rolf P. ENGELBERGER*, Daniel TETA†, Hughes HENRY $\ddagger$, Olivier De SENARCLENS*, \\ Benoît DISCHL*, Lucas LIAUDET§, Michel BURNIER†, Bernard WAEBER* and \\ François FEIHL* \\ *Division de Physiopathologie Clinique, Centre Hospitalier Universitaire Vaudois (CHUV) et Université de Lausanne (UNIL), \\ BHI0-70I Lausanne, Switzerland, † Service de Néphrologie, Centre Hospitalier Universitaire Vaudois (CHUV) et Université de \\ Lausanne (UNIL), BHI0-70I Lausanne, Switzerland, †Laboratoire Central de Chimie Clinique, Centre Hospitalier Universitaire \\ Vaudois (CHUV) et Université de Lausanne (UNIL), BHI0-70I Lausanne, Switzerland, and §Soins Intensifs de Médecine Adulte, \\ Centre Hospitalier Universitaire Vaudois (CHUV) et Université de Lausanne (UNIL), BHI0-70I Lausanne, Switzerland
}

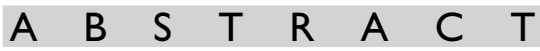

\begin{abstract}
End-stage renal disease patients have endothelial dysfunction and high plasma levels of ADMA (asymmetric $\omega-N^{G}, N^{G}$-dimethylarginine), an endogenous inhibitor of NOS (NO synthase). The actual link between these abnormalities is controversial. Therefore, in the present study, we investigated whether HD (haemodialysis) has an acute impact on NO-dependent vasodilation and plasma ADMA in these patients. A total of 24 patients undergoing maintenance HD (HD group) and 24 age- and gender-matched healthy controls (Control group) were enrolled. The increase in forearm SkBF (skin blood flow) caused by local heating to $4 l^{\circ} \mathrm{C}$ (SkBF4I), known to depend on endothelial NO production, was determined with laser Doppler imaging. SkBF4I was expressed as a percentage of the vasodilatory reserve obtained from the maximal SkBF induced by local heating to $43^{\circ} \mathrm{C}$ (independent of NO). In HD patients, SkBF4I was assessed on two successive HD sessions, once immediately before and once immediately after HD. Plasma ADMA was assayed simultaneously with MS/MS (tandem MS). In the Control group, SkBF4I was determined twice, on two different days, and plasma ADMA was assayed once. In HD patients, SkBF4I was identical before $(82.2 \pm 13.1 \%)$ and after $(82.7 \pm 12.4 \%) \mathrm{HD}$, but was lower than in controls (day I, $89.6 \pm 6.1$; day 2, $89.2 \pm 6.9 \% ; P<0.01$ compared with the HD group). In contrast, plasma ADMA was higher before $(0.98 \pm 0.17 \mu \mathrm{mol} / \mathrm{l})$ than after $(0.58 \pm 0.10 \mu \mathrm{mol} / \mathrm{l} ; P<0.0 \mathrm{I})$ HD. ADMA levels after HD did not differ from those obtained in controls $(0.56 \pm 0.11 \mu \mathrm{mol} / \mathrm{l})$. These findings show that HD patients have impaired NO-dependent vasodilation in forearm skin, an abnormality not acutely reversed by HD and not explained by ADMA accumulation.
\end{abstract}

\footnotetext{
Key words: asymmetric $\omega$ - $N^{\mathrm{G}}, N^{\mathrm{G}}$-dimethylarginine (ADMA), chronic haemodialysis, endothelium-dependent vasodilation, endstage renal disease, nitric oxide, skin blood flow.

Abbreviations: ADMA, asymmetric $\omega-N^{\mathrm{G}}, N^{\mathrm{G}}$-dimethylarginine; BMI, body mass index; BP, blood pressure; CKD, chronic kidney disease; CRF, chronic renal failure; $\mathrm{d}_{7}$-ADMA, $\left[2,3,3,4,4,5,5^{-2} \mathrm{H}_{7}\right]$-ADMA; DBP, diastolic BP; DDAH, dimethylarginine dimethylaminohydrolase; ESRD, end-stage renal disease; FMD, flow-mediated vasodilation; HD, haemodialysis; NOS, NO synthase; eNOS, endothelial NOS; PU, perfusion unit; SBP, systolic BP; SkBF, skin blood flow; $\mathrm{SkBF}_{\max }$, maximum SkBF; SPE, solid-phase extraction.

Correspondence: Dr François Feihl (email Francois.Feihl@chuv.ch).
} 


\section{INTRODUCTION}

Cardiovascular complications are the most important cause of mortality in ESRD (end-stage renal disease) patients [1]. In this population, one contributing factor to increased cardiovascular risk might be the accumulation of endogenous NOS (NO synthase) inhibitors such as ADMA (asymmetric $\omega-N^{G}, N^{G}$-dimethylarginine) [2,3]. This accumulation appears to be due in large part to a down-regulated expression of DDAH (dimethylarginine dimethylaminohydrolase), the enzyme which degrades ADMA [4]. In CKD (chronic kidney disease) patients, plasma ADMA levels are a strong independent predictor of kidney disease progression [5,6] and of all-cause cardiovascular mortality [7]. Furthermore, Matsumoto et al. [8] have demonstrated in a rat model of CRF (chronic renal failure) that ADMA is involved in peritubular capillary loss, tubulointerstitial fibrosis and proteinuria, thereby contributing to the progression of CKD.

ADMA accumulation can be a direct cause of endothelial dysfunction [9], which plays a pivotal role in the development of atherosclerosis [10]. Endothelial dysfunction, manifested by reduced endotheliumdependent vasodilation, exists even with a mild chronic impairment of renal function [11,12], and in uraemia, as in many other pathologies, it has been attributed to reduced bioavailability of endothelium-produced NO [13,14]. Elevated circulating levels of ADMA have been linked to endothelial dysfunction in hypercholesterolaemia [15] and in CKD patients [3,4]. The influence of a single HD (haemodialysis) session on plasma ADMA levels has been described in the literature as highly variable, with a mean decrease after HD ranging from 0 to $84 \%$ [16]. The impact of an HD-induced acute fall in plasma ADMA on endothelial NO-dependent vasodilation is not known.

The aim of the present study was to test in ESRD patients the hypothesis that an acute decrease in ADMA levels in plasma after a single HD session may improve endothelial dysfunction in the cutaneous microcirculation.

Part of this work was presented at the XLV ERAEDTA meeting, Stockholm, Sweden, 10-13 May 2008, and published in abstract form [16a].

\section{MATERIALS AND METHODS}

\section{Subjects}

A total of 24 patients on maintenance HD for more than 1 month were enrolled (HD group; Table 1). Patients with arteriovenous fistulas on both forearms, dermatological pathologies or treatment with organic nitrates were excluded. All HD patients were anuric except for six of them. The HD technical prescription during the HD investigational sessions is described in Table 2 (Table 2).
Table I Demographic and clinical characteristics of the HD patients

Values are means \pm S.D. ACEl, angiotensin-converting enzyme inhibitor; ARB, angiotensin II type I receptor.

\begin{tabular}{ll}
\hline Characteristic & HD group $(n=24)$ \\
\hline Age (years) & $67.9 \pm 13.6$ \\
Gender (male/female) $(n)$ & $18 / 6$ \\
BMI $\left(\mathrm{kg} / \mathrm{m}^{2}\right)$ & $25.6 \pm 4.5$ \\
Months on HD & $41.6 \pm 68.4$ \\
Underlying renal disease $(n)$ & \\
Diabetic nephropathy & 9 \\
Hypertensive nephrangiosclerosis & 17 \\
Chronic glomerulonephritis & 2 \\
Cyclosporine induced nephropathy & 2 \\
IgA nephropathy & 1 \\
Other/unknown & 6 \\
Co-morbidities ( $n$ ) & \\
Diabetes & 9 \\
Coronary heart disease & 8 \\
Hypercholesterolaemia & 12 \\
Polyneuropathy & 7 \\
Smokers & 8 \\
Medication ( $n$ ) & 8 \\
$\beta$-Adrenergic blockers & 13 \\
Calcium-channel blockers & 19 \\
ACEls & \\
ARBs & \\
Antiplatelet therapy & 11 \\
Diuretics & 8 \\
Statins & \\
Recombinant erythropoietin & \\
\hline & \\
\hline
\end{tabular}

The dialysate temperature was maintained constant at $37^{\circ} \mathrm{C}$. All patients had high-flux filters.

A total of 24 healthy subjects who were matched to the HD group for age and gender were recruited [Control group; age, $68.8 \pm 11.7$ years; 17 male and seven female; BMI (body mass index), $24.7 \pm 2.3 \mathrm{~kg} / \mathrm{m}^{2}$ ]. The control subjects were all non-smokers, did not have cardiovascular or kidney disease, diabetes or dermatological disease, and were not taking any medication.

All participants in the present study were Caucasians, as skin colour influences laser Doppler flowmetry.

The study was approved by the ethics committee of the University of Lausanne and conformed to the principles outlined in the Declaration of Helsinki. All participants gave written informed consent.

\section{Assessment of skin endothelial function}

The measurement of microvascular SkBF (skin blood flow) with laser Doppler flowmetry can be used for the non-invasive assessment of endothelial function in the human cutaneous microcirculation [17]. Local heating 
Table 2 Technical HD prescription

Values are means \pm S.D. $s p K t / V_{\text {urea }}$, single pool $K t / V_{\text {urea }}$, according to the second-generation Daugirdas formula [67]. Haemodiafiltration was always online.

Prescription

\begin{tabular}{lc}
\hline $\begin{array}{l}\text { Duration of HD }(\mathrm{min}) \\
\text { Filter type } \\
\quad \text { Polysulfone }\end{array}$ & $214.8 \pm 23.3$ \\
$\quad$ Polyamide & 13 out of 24 patients \\
HD & II out of 24 patients \\
Haemodiafiltration & 19 out of 24 patients \\
$\quad$ Substitution volume $(\mathrm{ml} / \mathrm{min})$ & 5 out of 24 patients \\
Blood flow rate $(\mathrm{ml} / \mathrm{min})$ & $89.0 \pm 5.7$ \\
Dialysate flow rate $(\mathrm{ml} / \mathrm{min})$ & $436.3 \pm 59.8$ \\
Ultrafiltration volume $(\mathrm{kg})$ & $490.4 \pm 26.9$ \\
$\mathrm{sp} K t / V_{\text {urea }}$ & $2.5 \pm 0.8$ \\
\end{tabular}

of the skin to temperatures below $42{ }^{\circ} \mathrm{C}$ typically induces a biphasic increase in SkBF with an initial peak and a secondary sustained plateau after $20-30 \mathrm{~min}$ (thermal hyperaemia). This plateau response is known to be primarily mediated by the local generation of NO [18], with recent findings supporting the production by eNOS (endothelial NOS), rather than nNOS (neuronal NOS) [19]. Thermal hyperaemia has been used in clinical studies to investigate endothelium-dependent NO release [20]. Its decrease has been shown to be of prognostic value for cardiovascular mortality in ESRD patients [21].

\section{Measurement of SkBF}

Laser Doppler flowmetry was carried out with a laser Doppler imager (LDI; Moor Instruments), as described previously $[22,23]$. This device allows the measurement of dermal microvascular blood flow in a region of interest with no skin contact. According to the principles of laser Doppler flowmetry, SkBF is expressed in PUs (perfusion units).

\section{Local thermal hyperaemia}

The change in SkBF induced by local warming of the skin was recorded by means of temperature-controlled waterfilled chambers as described previously [23,24]. Local temperature was set at $34^{\circ} \mathrm{C}$ until SkBF was stable, then was raised to $41^{\circ} \mathrm{C}$ in $60 \mathrm{~s}$ and maintained at this level for $28 \mathrm{~min}$. Subsequently, the temperature was increased to $43^{\circ} \mathrm{C}$ for another $15 \mathrm{~min}$ to induce $\mathrm{SkBF}_{\max }$ (maximum $\mathrm{SkBF})[25]$.

\section{Analytical methods}

\section{Plasma levels of ADMA}

ADMA determination in plasma was performed by electrospray MS/MS (tandem MS). To $60 \mu \mathrm{l}$ of plasma, $30 \mu \mathrm{l}$ of $\mathrm{d}_{7}$-ADMA $\left(\left[2,3,3,4,4,5,5-{ }^{2} \mathrm{H}_{7}\right]-\mathrm{ADMA}\right)$ at $1 \mu \mathrm{mol} / 1$ (Cambridge Isotope Laboratories), $106 \mu \mathrm{l}$ of water and
$4 \mu l$ of formic acid were added. The analytes were purified by $\mu$-SPE (micro-solid-phase extraction) using the Oasis MCX $\mu$ Elution Plate (Waters). The procedure comprised of what is typical for SPE: conditioning of the $\mu$-SPE wells by methanol, application of the diluted samples, wash steps with $2 \%(\mathrm{v} / \mathrm{v})$ formic acid and methanol, and finally elution with $1.25 \%(\mathrm{v} / \mathrm{v}) \mathrm{NH}_{4} \mathrm{OH}$ in water.

Chromatographic analysis was performed using a Rheos CPS-LC (Flux Instruments) and a PAL SYSTEM autosampler (CTC Analysis). Separation of the analytes was achieved at $30^{\circ} \mathrm{C}$ using an Atlantis HILIC silica $2.1 \times 50 \mathrm{~mm}$ column (Waters). The mobile phases used for the chromatographic separation were composed of $20 \mathrm{mmol} / \mathrm{l}$ ammonium formate, $0.4 \%(\mathrm{v} / \mathrm{v})$ formic acid in water and acetonitrile. The column effluent was monitored using a Triple Quadrupole TSQ Quantum Discovery (Thermo Scientific). The instrument was equipped with an electrospray interface and was controlled by the Xcalibur software (Thermo Scientific). The samples were analysed in the positive-ionization mode operating in a cone voltage of $4 \mathrm{kV}$. The tandem mass spectrometer was programmed using the SRM (selected reaction monitoring) mode to allow the $\left[\mathrm{MH}^{+}\right]$ions of ADMA at $\mathrm{m} / \mathrm{z} 203$ and that of the internal standard $\mathrm{d}_{7}$-ADMA at $\mathrm{m} / \mathrm{z} 210$ to pass through the first quadrupole $(\mathrm{Q} 1)$ and into the collision cell (Q2). The daughter ions for ADMA and $\mathrm{d}_{7-}$ ADMA are of $m / z$ 46. Calibration curves were computed using the ratio of the peak area of the analytes and internal standard using a weighted $\left(1 / x^{2}\right)$ least-squares linear regression analysis.

We did not assay the symmetric form of dimethyL-arginine [SDMA (symmetric $\omega$ - $N^{\mathrm{G}}, N^{\prime} \mathrm{G}$-dimethylarginine)], which is devoid of inhibitory effect on NOS activity [3].

\section{Plasma levels of L-arginine}

For practical reasons, L-arginine levels in plasma were measured using a protocol in our laboratory based on HPLC. The analysis was performed using an Agilent 1100 HPLC system. A reverse-phase was used for chromatographic separation [Zorbax Eclipse $\mathrm{C}_{18}$ column AAA $(4.6 \times 150 \mathrm{~mm} ; 3.5 \mu \mathrm{mol} / \mathrm{l})$; Agilent Technologies]. Detection was done by fluorescence measurements at $340 \mathrm{~nm}$ (excitation) and $450 \mathrm{~nm}$ (emission). ChemStation Rev B 03-01 software (Agilent Technologies) was used for data acquisition and analysis.

An internal standard (50 $\mu \mathrm{l}$ of $1250 \mu \mathrm{mol} / 1 \delta$-glucosaminic acid in $160 \mathrm{~g} / 15$-sulfosalicylic acid) was added to $200 \mu$ l of plasma. The samples were mixed thoroughly and incubated on ice for $1 \mathrm{~h}$. The tubes were centrifuged at $20800 \mathrm{~g}$. Then, $30 \mu \mathrm{l}$ of $200 \mathrm{mmol} / 1 \mathrm{Na}_{2} \mathrm{HPO}_{4}(\mathrm{pH} 7.8)$ was added to $120 \mu \mathrm{l}$ of supernatant. The samples were transferred into HPLC vials for injections.

Automatic pre-column derivatization with OPA$3 \mathrm{MPA}$ was performed at room temperature $\left(21-24^{\circ} \mathrm{C}\right)$ 
using an autosampler program in accordance with the manufacturer's instructions (Agilent Technologies). The mobile phase A was $40 \mathrm{mmol} / 1 \mathrm{NaH}_{2} \mathrm{PO}_{4}(\mathrm{pH} 7.8$ ), and mobile phase $\mathrm{B}$ was acetonitrile/methanol/water (9:9:2, by vol.). The separation was obtained at a flow rate of $1 \mathrm{ml} / \mathrm{min}$ with a gradient program that allowed for $2 \mathrm{~min}$ of $0 \% \mathrm{~B}$, followed by a $26 \mathrm{~min}$ step that raised mobile phase B to $20 \%$. Then, washing at $100 \% \mathrm{~B}$ for $10 \mathrm{~min}$ and the equilibration steps at $0 \% \mathrm{~B}$ for $10 \mathrm{~min}$ were performed for a total run of $48 \mathrm{~min}$.

\section{Experimental protocol}

\section{HD group}

Each subject was examined on two separate visits 2 or 3 days apart. Caffeine-containing beverages were avoided on the day of the experiments, and smokers were not allowed to smoke for at least $8 \mathrm{~h}$ before examination. The visits were on two successive HD sessions. Thermal hyperaemia was recorded, and blood was drawn for the determination of plasma ADMA and $\mathrm{L}$-arginine at the same visit, once in the hour before and once immediately after $\mathrm{HD}$, in a randomized order. The blood sample after the HD session was collected after a short equilibration period, as usually determined in order to measure $K t / V_{\text {urea }}$ [dialysis quality; where $K$ is dialyser clearance for urea, $t$ is time, and $V_{\text {urea }}$ is the urea distribution volume (i.e. total body water)] in a standardized fashion. This was as follows: dialysate flow stopped, ultrafiltration stopped, blood flow reduced to $100 \mathrm{ml} / \mathrm{min}$ for $3 \mathrm{~min}$, and blood taken from the arterial line. Twelve patients attending the morning HD session were thus examined in the morning period, and the 12 patients attending the afternoon HD session were assessed in the afternoon. Investigations were not performed before and after the same HD session for the following reasons: (i) we wanted to record thermal hyperaemia on exactly the same skin site on both occasions in order to avoid potential confounding by spatial variation of the vasodilatory response [22], and (ii) we have recently published results indicating that thermal hyperaemia recorded on a particular site can be diminished by previous heating of this site carried out a few hours before [24]. Measurements were performed in the forearm contralateral to the arteriovenous vascular access. After an acclimatization period of $10 \mathrm{~min}$, the subjects were examined in the supine position with the forearm under investigation supported by a vacuum splint. The exact location of the site on the examined forearm was marked on a transparent acetate film, together with the anatomical outline of the forearm, in order to exactly locate the same site for the SkBF measurements performed during the second visit [22].

BP (blood pressure) and heart rate were measured before and after the recording of thermal hyperaemia on the contralateral arm using an automated electronic device (Datascope Accutorr 1A; MS Cardio-Medical).
Skin temperature was also systematically measured using a cutaneous probe (G. Métraux). The investigations were carried out in a quiet room with air conditioning. Ambient temperature was systematically measured and ranged from $23-26^{\circ} \mathrm{C}$.

\section{Control group}

Each participant in this group also had two separate measurement sessions at the same time of day as in the HD group (sessions 'before' and 'after'), also on two different days. The experimental protocol was identical with that followed in the HD group, except for the absence of HD and for the fact that plasma ADMA was determined only once.

\section{Data analysis}

Values are presented as means \pm S.D., or medians (range) in the case of asymmetrical distributions. To take into account the biphasic SkBF response to local heating $[18,23]$, local thermal hyperaemia was summarized as: (i) baseline (average SkBF of the first two measurements); (ii) initial peak (maximal SkBF in the first 6 min after the beginning of heating); (iii) nadir (minimal SkBF after the initial peak); (iv) plateau (average $\mathrm{SkBF}$ of the last 5 min at $41^{\circ} \mathrm{C}$ ); and (v) $\mathrm{SkBF}_{\max }$ (average $\mathrm{SkBF}$ of the last 5 min at $\left.43^{\circ} \mathrm{C}\right)$. $\mathrm{SkBF}_{\max }$ is expressed in PUs, whereas all of the other SkBF measurements are expressed as a percentage of $\mathrm{SkBF}_{\max }$ for normalization purposes [17]. Contrary to plateau $\mathrm{SkBF}, \mathrm{SkBF}_{\max }$ is independent of endothelial NO, as are the initial peak and the nadir $[18,19]$.

Statistical analysis of the SkBF data was carried out with univariate repeated-measures ANOVA. When the $F$ value was significant, pairwise comparisons were carried out with modified Student's $t$ tests (i.e. Fisher-protected least-significant difference). The $\alpha$ level of all tests was set at 0.05 . All computations were performed with JMP software version 5.0.2 (SAS Institute).

\section{RESULTS}

Vital parameters and skin temperature values are summarized in Table 3. SBP and DBP (systolic and diastolic $\mathrm{BP}$ s respectively) were significantly higher in $\mathrm{HD}$ patients than in control subjects $(P<0.01)$. Compared with the Control group, mean $\mathrm{BP}$ in the $\mathrm{HD}$ group was significantly higher before $(P<0.01)$, but similar after, the HD session. HD did not affect heart rate, which was significantly higher in HD patients than in controls $(P<0.01)$. Skin temperature at the forearm level was slightly lower in HD patients than in controls $(P<0.05)$ and was not influenced by HD. This difference may be explained, at least in part, by a somewhat lower ambient temperature in the examination room used with the HD patients, which for practical reasons was located within 
Table 3 Vital parameters and response of SkBF to local heating $\left(4 I^{\circ} \mathrm{C}\right)$

Values are means \pm S.D. ${ }^{* *} P<0.01$ compared with after HD. ${ }^{\circ} P<0.05$ and ${ }^{\circ} P<0.01$ compared with the Control group.

\begin{tabular}{|c|c|c|c|c|}
\hline \multirow[b]{2}{*}{ Parameter } & \multicolumn{2}{|l|}{ HD group } & \multicolumn{2}{|l|}{ Control group } \\
\hline & Before HD & After HD & 'Before' & 'After' \\
\hline \multicolumn{5}{|l|}{ Vital parameter } \\
\hline SBP (mmHg) & $146 \pm 23^{* * 00}$ & $125 \pm 20$ & $124 \pm 20$ & $125 \pm 18$ \\
\hline DBP (mmHg) & $76 \pm 11 * * \circ 0$ & $66 \pm 14^{\circ}$ & $70 \pm 14$ & $71 \pm 11$ \\
\hline Mean BP (mmHg) & $99 \pm 13^{* * 00}$ & $86 \pm 13$ & $88 \pm 13$ & $89 \pm 14$ \\
\hline Heart rate (beats/min) & $75 \pm 13^{\circ 0}$ & $74 \pm 12^{\circ}$ & $63 \pm 8$ & $61 \pm 7$ \\
\hline Weight $(\mathrm{kg})$ & $75.8 \pm 17^{* * \circ \circ}$ & $73.6 \pm 16.4$ & $73.2 \pm 10.8$ & $73.2 \pm 10.8$ \\
\hline Skin temperature $\left({ }^{\circ} \mathrm{C}\right)$ & $32.5 \pm 0.8^{\circ}$ & $32.6 \pm 1.0^{\circ}$ & $33.2 \pm 1.1$ & $33.3 \pm 1.1$ \\
\hline Ambient temperature $\left({ }^{\circ} \mathrm{C}\right)$ & $24.2 \pm 0.4^{\circ}$ & $24.6 \pm 0.6^{\circ}$ & $24.8 \pm 0.7$ & $25.0 \pm 0.8$ \\
\hline \multicolumn{5}{|l|}{ SkBP response } \\
\hline Baseline $\left(\%\right.$ of $\left.S k B F_{\max }\right)$ & $16.1 \pm 4.9$ & $16.7 \pm 6.1$ & $14.4 \pm 5.5$ & $14.7 \pm 6.0$ \\
\hline Initial peak $\left(\%\right.$ of $\left.\mathrm{SkBF}_{\max }\right)$ & $73.4 \pm 13.3$ & $72.4 \pm 20.4$ & $74.2 \pm 8.6$ & $78.6 \pm 10.6$ \\
\hline Nadir $\left(\%\right.$ of $\left.\mathrm{SkBF}_{\max }\right)$ & $51.5 \pm 15.5$ & $50.5 \pm 17.9$ & $59.0 \pm 9.9$ & $59.0 \pm 14.2$ \\
\hline Plateau $\left(\%\right.$ of $\left.S k B F_{\max }\right)$ & $82.2 \pm 13.1^{\circ 0}$ & $82.7 \pm 12.4^{\circ}$ & $89.6 \pm 6.1$ & $89.2 \pm 6.9$ \\
\hline $\mathrm{SkBF}_{\max }(\mathrm{PUs})$ & $491 \pm 163^{\circ 0}$ & $475 \pm 174^{\circ \circ}$ & $632 \pm 92$ & $635 \pm 129$ \\
\hline
\end{tabular}

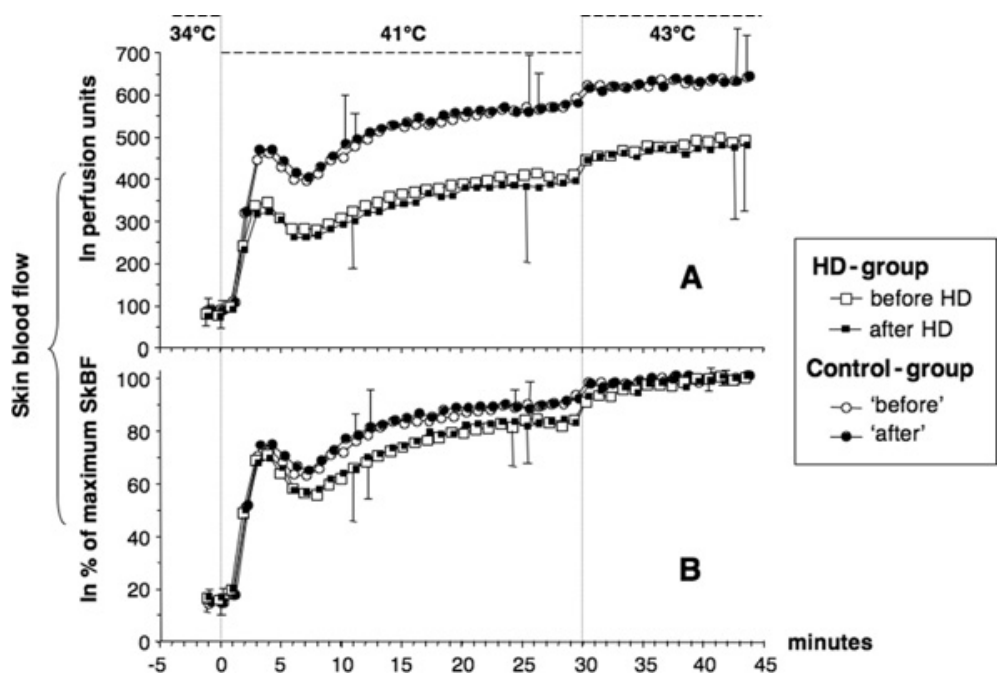

Figure I Response of SkBF to local heating in patients on chronic HD for ESRD and in control subjects

(A) SkBF is expressed in PUs; (B) SkBF is expressed as a percentage of the maximum SkBF at $43^{\circ}$ C. Patients on HD and control subjects were matched for age and gender. Before HD, the hour that preceded one HD session; after HD, the hour that followed another HD session; 'before' and 'after', two measurements made 2 or 3 days apart in the same control subject at the same time of day as in the patients. The two HD sessions (or in controls the two measurement sessions) were 2 or 3 days apart. Values are means \pm S.D. of 24 subjects per group.

the HD ward, whereas the control subjects were studied in the physiology laboratory.

As shown in Figure 1 and Table 3, $\mathrm{SkBF}_{\max }$ [i.e. elicited by heating at $43^{\circ} \mathrm{C}$ (NO-independent) and expressed in $\mathrm{PUs}$ ] was significantly lower in the HD group than in the Control group, and completely unaffected by HD. When expressed as a percentage of $S \mathrm{kBF}_{\max }$, the plateau $\mathrm{SkBF}$ [i.e. after $30 \mathrm{~min}$ of heating at $41^{\circ} \mathrm{C}(\mathrm{NO}$-dependent)] was significantly lower in HD patients than in controls, whereas the initial peak and the nadir responses (both independent of endothelial NO production $[18,19]$ ) did not differ between the groups. None of the variables derived from thermal hyperaemia was affected by HD. In the Control group, the first and second thermal hyperaemia were identical in every respect.

Measurements in the morning did not differ from those in the afternoon in both HD patients and the Control group (results not shown). There was no correlation between the temperature of unheated skin (measured in the vicinity of the thermally probed area) and any of the parameters derived from thermal hyperaemia. This lack of correlation makes it very unlikely that the slightly lower 


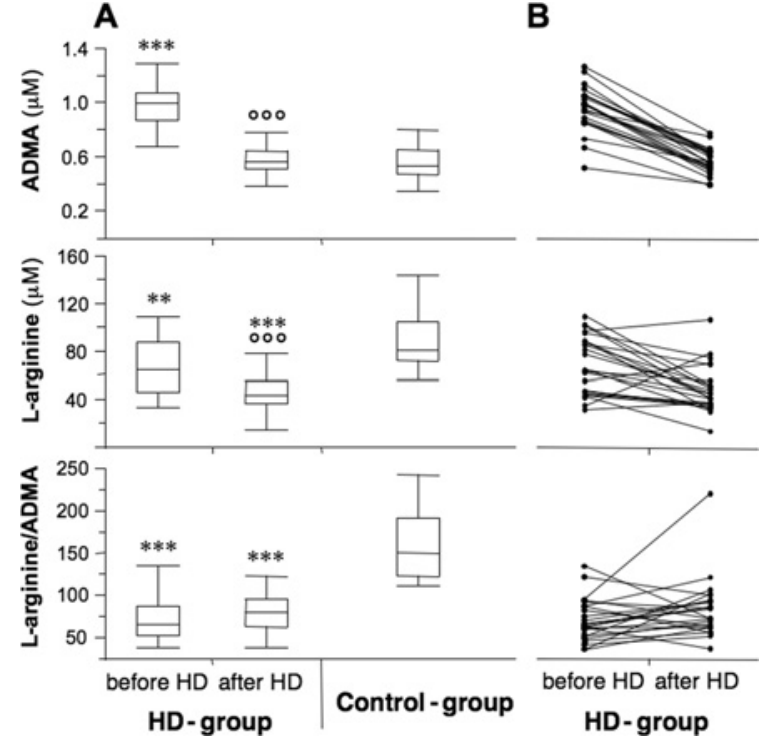

Figure 2 Effects of HD on plasma levels of ADMA and L-arginine

In patients on HD, plasma ADMA and L-arginine levels were assessed in the hour that preceded one HD session (before HD) and immediately after another HD session (after HD). Plasma ADMA was obtained only once in the Control group. (A) Boxes indicate the 25th, 50th and 75th percentile, and whiskers indicate the 5th and 95th percentile. (B) Individual changes before and after HD. ${ }^{* * P}<0.01$ and ${ }^{* * *} P<0.001$ compared with the Control group; ${ }^{\circ 00} P<0.001$ compared with 'before HD'.

unheated skin temperature of the patients could account for the differences between the groups shown in Figure 1 and Table 3.

Blood was drawn for the determination of plasma ADMA and $\mathrm{L}$-arginine levels simultaneously with SkBF measurements on both sessions in the HD group, and on only one session in the Control group (Figure 2). In the $\mathrm{HD}$ group, $\mathrm{ADMA}$ and $\mathrm{L}$-arginine levels were higher before HD $(0.98 \pm 0.17$ and $70 \pm 24 \mu \mathrm{mol} / 1$ respectively) than after $\mathrm{HD}(0.58 \pm 0.10$ and $49 \pm$ $19 \mu \mathrm{mol} / 1$ respectively; $P<0.001$ for ADMA and $P=0.005$ for L-arginine). Before HD, ADMA levels were also significantly higher and $\mathrm{L}$-arginine levels significantly lower than in the Control group $(0.56 \pm 0.11$ and $88 \pm$ $23 \mu \mathrm{mol} / 1 ; P<0.001$ for both analytes). After HD, ADMA levels of the patients did not differ from the values of control subjects, whereas L-arginine was considerably lower $(49 \pm 19 \mu \mathrm{mol} / \mathrm{l} ; P<0.001)$. The median relative decreases in plasma ADMA and L-arginine levels induced by $\mathrm{HD}$ were -40 and $-29 \%$ respectively, of the predialysis value, with a substantial variability between patients (range for ADMA, -20 to $-52 \%$; range for L-arginine, -66 to $+117 \%$ ) (Figure $2 \mathrm{~B}$ ).

The plasma concentration L-arginine/ADMA ratio has been advocated as surrogate for NO production capacity [15]. In patients, this ratio was considerably lower than in

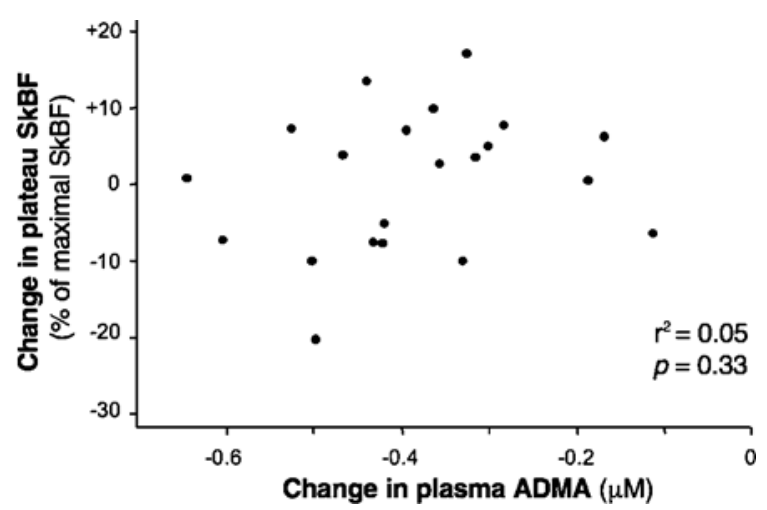

Figure 3 Correlation between changes in plasma levels of ADMA induced by HD and the corresponding changes in the plateau SkBF response to local heating $\left(4 I^{\circ} \mathrm{C}\right)$

Changes in $\mathrm{SkBF}$ are expressed as a percentage of $\mathrm{SkBF}_{\max }$ elicited by subsequent heating to $43^{\circ} \mathrm{C}$ (see Figure I).

control subjects [before HD, 66 (38-136) compared with $150(112-242)$ in the Control group; $P<0.001]$ and there was a small, but non-significant, increase in this ratio after HD [80 (38-222); $P=0.06$ ] (Figure 2).

There was no correlation between the changes observed between the two HD sessions in the NOdependent SkBF plateau and the corresponding changes in plasma ADMA $\left(r^{2}=0.05, P=0.33\right.$; Figure 3), plasma L-arginine $\left(r^{2}=0.00, P=0.95\right)$ and $\mathrm{L}$-arginine/ADMA ratio $\left(r^{2}=0.02, P=0.56\right)$.

\section{DISCUSSION}

In the present study, we have found that HD markedly and transiently decreased the plasma levels of both $\mathrm{L}$-arginine and ADMA, with only a small non-significant increase in the $\mathrm{L}$-arginine/ADMA ratio. Concomitantly, there was no acute influence of HD on an NO-dependent vasodilatory response in the skin microcirculation. These results raise the possibility that, in ESRD patients, removal of endogenous NOS inhibitors by HD is not efficient in improving endothelial function due to the concomitant changes induced in the availability of L-arginine. Alternatively, mechanisms other than or in addition to inhibition of eNOS by accumulated ADMA may be responsible for endothelial dysfunction in ESRD.

\section{Plasma L-arginine and ADMA levels}

\section{Pre-dialysis values}

In the HD group before dialysis, plasma L-arginine was $30 \%$ lower and plasma ADMA was $40 \%$ higher in comparison with values from the Control group, which was matched for age and gender. Although not reported constantly [26-28], an abnormally low level of circulating $\mathrm{L}$-arginine has been a frequent finding in previous studies 
of ESRD patients [29-33], possibly related to deficient nutritional status [31], diminished L-arginine synthesis by the kidney, chronic loss of this amino acid in the dialysate [34], or stimulated transport into cells via the $\mathrm{y}^{+}$cationic amino-acid transporter [33].

Retention of ADMA has been uniformly found in ESRD patients, although the relative increase in the plasma level of this arginine analogue has varied between studies from 1.3 to 10 times the normal value (reviewed in [16]). Our pre-dialysis and control ADMA results are in agreement with those obtained either with HPLC by Fleck et al. [29], Wahbi et al. [35] and Schiel et al. [36] or with LC-MS (as in the present study) by MartensLobenhoffer et al. [37].

\section{Acute impact of HD}

In ESRD patients, the short-term effect of a single HD session on the plasma levels of L-arginine has been extremely variable between studies, with some finding no change $[27,28,32,38]$ while others reported decreases ranging from $10-70 \%$ of pre-dialysis values [26,39-41]. The present study clearly belongs to the second category (Figure 2), although the results differed considerably between patients, possibly because of a variable redistribution of $\mathrm{L}$-arginine between intracellular and extracellular pools (keeping in mind that the former is by far the larger) [42].

A recent systematic review identified 19 clinical studies where the acute impact of HD on ADMA plasma levels was documented in ESRD patients [16]. Findings were highly variable between studies, with a mean percentage reduction ranging from 0 to $84 \%$. [16]. In the present study, HD appeared efficient at decreasing ADMA plasma levels (a mean decrease of $40 \%$ ), although there was substantial variability between patients in that respect. Low ADMA clearance during HD compared with other substances of similar chemical structure might be explained by significant protein binding [43]. The influence of oxidative stress, pro-inflammatory cytokines and $\mathrm{pH}$ changes on catabolism of ADMA as well as on its uptake and release by erythrocytes [44] or other cells [45] may also be involved.

\section{Thermal hyperaemia as a non-invasive means to evaluate NO-dependent vasodilation in CKD}

Two clinical studies have found that microvascular endothelial function, as assessed with local thermal hyperaemia, was depressed in ESRD patients [21,46], and the present study confirms these results (Table 3). Furthermore, a prospective study of CRF patients showed that impaired skin thermal hyperaemia was predictive of cardiovascular mortality after 2 years, independently of other conventional risk factors [21]. Collectively, these findings support the validity of a diminished plateau of thermal hyperaemia as an indicator of endothelial dysfunction in the setting of CKD.

In our present study, the interpretation of differences in plateau $\mathrm{SkBF}$ at $41^{\circ} \mathrm{C}$ between patients and controls is complicated by the unequal vasodilatory reserve of the skin microcirculation in the two groups, as shown by the markedly different $\mathrm{SkBF}_{\max }$ (Figure 1 and Table 3). In contrast with the submaximal SkBF plateau, $\mathrm{SkBF}_{\max }$ is insensitive to NOS inhibitors [18] and is thought to depend directly on the local density of microvessels (i.e. the vasodilatory reserve) [47]. In view of the well-established association between hypertension and rarefaction of skin capillaries [48] and considering the markedly higher BP in the HD group compared with the Control group (Table 3), it appears likely that the lower $\mathrm{SkBF}_{\max }$ measured in patients on $\mathrm{HD}$ was due, at least in part, to the hypertension-related reduction in skin capillary density. Another possible explanation relates to the well-known angiogenic effect of NO [49]. In the mouse, chronic administration of a NOS inhibitor induced capillary rarefaction, at least in the kidney medulla [50]. Thus microvascular rarefaction in the HD group might also have been promoted by chronic $\mathrm{NO}$ deficiency, which is characteristic of CKD and can be due, in part, to ADMA accumulation [34].

In view of these considerations, information on functional (as opposed to structural) mechanisms which potentially participate in the observed difference in thermal hyperaemia between the two study groups can only be extracted by comparing the vasodilatory responses normalized to $\mathrm{SkBF}_{\max }$, as we have done in the present study. The normalized NO-dependent [18] plateau SkBF at $41^{\circ} \mathrm{C}$ was lower in the $\mathrm{HD}$ group, but the normalized NO-independent [18] early peak was not (Table 3). These observations support a specific impairment of NO-mediated vasodilation in the skin microcirculation of renal failure patients.

\section{Impact of HD on thermal hyperaemia}

The HD prescription included the withdrawal of an amount of fluid sufficient to cause significant hypovolaemia (i.e. a mean ultrafiltration volume of 2.5 litres; Table 2), thus explaining the fall in BP that occurred in the course of the session (Table 3 ). This in turn may have triggered a baroreflex that could have had an impact upon skin vasoreactivity.

Interestingly, despite an important $\mathrm{BP}$ decrease during $\mathrm{HD}$, basal SkBF as well as $\mathrm{SkBF}_{\max }$ were not affected (Table 3). This suggests stable haemodynamic conditions in the cutaneous microcirculation even with important systemic haemodynamic modifications, making this method an interesting tool for the assessment of microvascular function in various conditions.

The actual impact of HD on endothelial function remains controversial. We did not find any difference in the thermal hyperaemic response before and after HD. 
Therefore, at least in the dermal microcirculation, HD does not appear to negatively or positively influence NO-dependent vasodilation in the short term, although its long-term impact in that respect cannot be inferred from our present findings. Our present results are consistent with some, but not all, previous findings made in patients on maintenance HD. The HD session had no effect on FMD (flow-mediated vasodilation) of the brachial artery [51], endothelium-dependent vascular reactivity assessed by applanation tonometry [28] or the response of the skin microcirculation to iontophoretic application of acetylcholine [52], an endotheliumdependent vasodilator. However, some investigators have found that endothelium-dependent vasodilation was acutely reduced after $\mathrm{HD}$, possibly because of the induced oxidative stress [53,54], the amount of which appears to depend on the type of dialysis filter used [55]. Improvement in endothelial function immediately after the HD session has also been reported [26,56,57]; however, we emphasize that, with one exception [52], all of these studies did not specifically assess endotheliumdependent vasodilation in the microcirculation.

\section{ADMA and NO-dependent vasodilation in CKD}

In the present study, we observed no correlation between plasma ADMA levels and endothelial NO-dependent vasodilation in the cutaneous microcirculation (Figure 3). More importantly, HD acutely reduced the plasma concentration of ADMA (Figure 2), but did not have any impact on NO-dependent vasodilation (Figure 1).

Our results are consistent with the findings of Chan et al. [58], who observed a complete dissociation between the changes in FMD and the changes in plasma ADMA levels which followed an increase in the dose of dialysis (i.e. a switch from conventional to nocturnal HD). Another study in patients on peritoneal dialysis reported that ADMA levels were related to basal, but not to acetylcholine-stimulated, $\mathrm{NO}$ bioactivity in the forearm circulation [59]. Cross et al. [56] did not find any correlation before and after an HD session between plasma ADMA or homocysteine concentrations and FMD and they concluded that the impaired conduit artery endothelial function in ESRD was due to the total burden of circulation inhibitors rather any single molecular species. On the other hand, Yilmaz et al. [60] found a significant negative correlation between FMD and ADMA levels before and 4 weeks after kidney transplantation, suggesting that increased ADMA levels might be one of the contributors to endothelial dysfunction in ESRD patients. However, their study population was much younger (mean age, 27.9 \pm 9.1 years) than those in the studies by Chan et al. [58] (41 \pm 2 years), Cross et al. [56] ( $43 \pm 3.5$ years) and ours (the present study; $68 \pm 14$ years), and the dialysis time of these patients before transplantation was not reported. In CRF, it is conceivable that the contribution of ADMA accumulation to impaired $\mathrm{NO}$-dependent vasodilation varies with patient age and/or disease duration in this setting.

The dissociation between changes in ADMA levels and changes in NO-dependent vasodilation observed in two studies as well as in our present study could be due to a concomitant reduction in NOS substrate availability, as possibly reflected by the acute decrease in plasma levels of L-arginine caused by HD (Figure 2). However, this is not supported by the findings of Cross et al. [56], who examined ESRD patients immediately before an HD session and were unable in these conditions to augment the NO-dependent vasodilation of the brachial artery (FMD) or of the forearm microvasculature (intra-arterial infusion of acetylcholine) by the systemic or intra-arterial infusion of L-arginine [61]. Another explanation might reside in the capacity of endothelial cells to concentrate ADMA. Cellular studies on bovine aortic endothelial cells have shown that intracellular ADMA levels could be 5-10 times higher than outside the cell [45]. There is a continuous low-level production of ADMA from the proteolysis of methylated arginine residues on various proteins [3], but its concentration is kept below a threshold concentration for inhibition of NOS by the activity of DDAH, the enzyme which degrades ADMA [4]. However under specific conditions, such as the addition of ADMA to the medium of cultured endothelial cells [45], administration of exogenous ADMA to experimental animals or humans [62] and DDAH deficiency in mice [9], intracellular ADMA may reach levels sufficient to inhibit NOS function and endothelium-dependent vasodilation. To date, it is not known how the intracellular environment tracks the extracellular concentration of ADMA when the latter varies rapidly. Nor is it clear whether high extracellular ADMA has biological effects in its own right or is merely a marker of high intracellular levels [3]. Alternatively, our results could mean that inhibition of NOS by accumulated ADMA is not the main culprit for reduced NO bioactivity in ESRD patients. Other potential mechanisms include scavenging of $\mathrm{NO}$ by ROS (reactive oxygen species), reduced expression of eNOS [4], possibly mediated by the accumulation of advanced glycation end-products [63], deficient supply of L-arginine or inhibition of $\mathrm{L}$-arginine transport into cells [34].

\section{Study limitations}

One limitation of the present study is that the potential vascular impact of $\mathrm{HD}$ was not tested in isovolaemic conditions, as shown by the substantial ultrafiltration volume withdrawn from patients (Table 2). The resulting decrease in BP (Table 3) may have triggered a baroreflex-mediated sympatho-adrenergic activation, with the resulting vasoconstriction then masking any 
positive influence of reduced ADMA levels on thermal hyperaemia. Although not supported by the absence of any effect of HD on basal SkBF (Table 3), this interpretation of our findings cannot be ruled out. In practical terms, however, our results would still imply a limited or non-existent overall impact of acutely reduced ADMA levels on NO-dependent skin vasodilation, since $\mathrm{HD}$ is not usually carried out in isovolaemic conditions.

The temperature of the dialysate was kept at $37^{\circ} \mathrm{C}$. In such conditions, it is possible that $\mathrm{HD}$ caused an increase in core temperature [64], thus adding a complicating influence on the regulation of SkBF [65]. However, if there were core temperature changes in our present study, they appear to have had a minimal influence on the cutaneous microcirculation, since skin temperature as well as basal SkBF were unaffected by HD (Table 3).

Another possible limitation is the fact that microvascular reactivity as well as blood parameters were not determined before and after the same HD session, for the specific reasons indicated in the Materials and methods section. However, this feature of our study design has limited potential for confounding, because, in every patient, HD prescription was identical between the two successive HD sessions. In stable ESRD patients (as were those of the present study), haemodynamic conditions either before or after HD are reproducible between HD sessions [66].

Finally, for the reasons explained in the Materials and methods section, plasma levels of ADMA and L-arginine were assayed with different methods. As long as each analyte was consistently assayed with the same technique, however, the validity of comparisons made between the groups as well as within the HD group (Figure 3) should not be affected.

\section{Conclusions}

In summary, the present study shows for the first time that endothelial NO-dependent vasodilation in the cutaneous microcirculation is not influenced by the plasma level of ADMA in patients on maintenance HD. These results suggest that mechanisms other than or in addition to inhibition of eNOS by accumulated ADMA are responsible for endothelial dysfunction in these patients. They call into question the concept that the accumulation of ADMA is a causal factor for the increased cardiovascular risk in ESRD patients and suggest that ADMA is more likely to represent just a marker of the highly atherogenic environment caused by CKD.

\section{ACKNOWLEDGEMENTS}

We gratefully acknowledge the help provided throughout the study by the nursing staff at the outpatient dialysis unit. We also thank all of the study participants for their time and patience.

\section{FUNDING}

This work was supported by Genzyme Switzerland, and by institutional funds.

\section{REFERENCES}

1 Foley, R. N., Parfrey, P. S. and Sarnak, M. J. (1998) Clinical epidemiology of cardiovascular disease in chronic renal disease. Am. J. Kidney Dis. 32, S112-S119

2 Zoccali, C. (2006) Traditional and emerging cardiovascular and renal risk factors: an epidemiologic perspective. Kidney Int. 70, 26-33

3 Vallance, P. and Leiper, J. (2004) Cardiovascular biology of the asymmetric dimethylarginine:dimethylarginine dimethylaminohydrolase pathway. Arterioscler. Thromb. Vasc. Biol. 24, 1023-1030

4 Tatematsu, S., Wakino, S., Kanda, T., Homma, K., Yoshioka, K., Hasegawa, K., Sugano, N., Kimoto, M., Saruta, T. and Hayashi, K. (2007) Role of nitric oxide-producing and -degrading pathways in coronary endothelial dysfunction in chronic kidney disease. J. Am. Soc. Nephrol. 18, 741-749

5 Fliser, D., Kronenberg, F., Kielstein, J. T., Morath, C., Bode-Boger, S. M., Haller, H. and Ritz, E. (2005) Asymmetric dimethylarginine and progression of chronic kidney disease: the mild to moderate kidney disease study. J. Am. Soc. Nephrol. 16, 2456-2461

6 Ravani, P., Tripepi, G., Malberti, F., Testa, S., Mallamaci, F. and Zoccali, C. (2005) Asymmetrical dimethylarginine predicts progression to dialysis and death in patients with chronic kidney disease: a competing risks modeling approach. J. Am. Soc. Nephrol. 16, 2449-2455

7 Zoccali, C., Bode-Boger, S., Mallamaci, F., Benedetto, F., Tripepi, G., Malatino, L., Cataliotti, A., Bellanuova, I., Fermo, I., Frolich, J. and Boger, R. (2001) Plasma concentration of asymmetrical dimethylarginine and mortality in patients with end-stage renal disease: a prospective study. Lancet 358, 2113-2117

8 Matsumoto, Y., Ueda, S., Yamagishi, S., Matsuguma, K., Shibata, R., Fukami, K., Matsuoka, H., Imaizumi, T. and Okuda, S. (2007) Dimethylarginine

dimethylaminohydrolase prevents progression of renal dysfunction by inhibiting loss of peritubular capillaries and tubulointerstitial fibrosis in a rat model of chronic kidney disease. J. Am. Soc. Nephrol. 18, 1525-1533

9 Leiper, J., Nandi, M., Torondel, B., Murray-Rust, J., Malaki, M., O’Hara, B., Rossiter, S., Anthony, S., Madhani, M., Selwood, D. et al. (2007) Disruption of methylarginine metabolism impairs vascular homeostasis. Nat. Med. 13, 198-203

10 Ross, R. (1993) The pathogenesis of atherosclerosis: a perspective for the 1990s. Nature 362, 801-809

11 Kari, J. A., Donald, A. E., Vallance, D. T., Bruckdorfer K. R., Leone, A., Mullen, M. J., Bunce, T., Dorado, B., Deanfield, J. E. and Rees, L. (1997) Physiology and biochemistry of endothelial function in children with chronic renal failure. Kidney Int. 52, 468-472

12 Thambyrajah, J., Landray, M. J., McGlynn, F. J., Jones, H. J., Wheeler, D. C. and Townend, J. N. (2000) Abnormalities of endothelial function in patients with predialysis renal failure. Heart 83, 205-209

13 Lerman, A. and Burnett, Jr, J. C. (1992) Intact and altered endothelium in regulation of vasomotion. Circulation $\mathbf{8 6}$, III12-III19

14 Passauer, J., Pistrosch, F., Bussemaker, E., Lassig, G., Herbrig, K. and Gross, P. (2005) Reduced agonist-induced endothelium-dependent vasodilation in uremia is attributable to an impairment of vascular nitric oxide. J. Am. Soc. Nephrol. 16, 959-965 
15 Boger, R. H., Bode-Boger, S. M., Szuba, A., Tsao, P. S., Chan, J. R., Tangphao, O., Blaschke, T. F. and Cooke, J. P. (1998) Asymmetric dimethylarginine (ADMA): a novel risk factor for endothelial dysfunction: its role in hypercholesterolemia. Circulation 98, 1842-1847

16 Jacobi, J. and Tsao, P. S. (2008) Asymmetrical dimethylarginine in renal disease: limits of variation or variation limits? A systematic review. Am. J. Nephrol. 28, $224-237$

16a Engelberger, R., Teta, D., Henri, H., Dischl, B., De Senarclens, O., Liaudet, L., Feihl, F., B. Waeber, B. and M. Burnier, M. (2008) Haemodialysis acutely reduces plasma asymetric dimethylarginine without reversing impaired nitric oxide dependent vasodilation. Nephrol. Dialysis Transplant. Plus 1 (Suppl. 2), ii418

17 Cracowski, J. L., Minson, C. T., Salvat-Melis, M. and Halliwill, J. R. (2006) Methodological issues in the assessment of skin microvascular endothelial function in humans. Trends Pharmacol. Sci. 27, 503-508

18 Minson, C. T., Berry, L. T. and Joyner, M. J. (2001) Nitric oxide and neurally mediated regulation of skin blood flow during local heating. J. Appl. Physiol. 91, 1619-1626

19 Kellogg, Jr, D. L., Zhao, J. L. and Wu, Y. (2008) Neuronal nitric oxide synthase control mechanisms in the cutaneous vasculature of humans in vivo. J. Physiol. 586, 847-857

20 Medow, M. S., Minson, C. T. and Stewart, J. M. (2005) Decreased microvascular nitric oxide-dependent vasodilation in postural tachycardia syndrome. Circulation 112, 2611-2618

21 Kruger, A., Stewart, J., Sahityani, R., O’Riordan, E., Thompson, C., Adler, S., Garrick, R., Vallance, P. and Goligorsky, M. S. (2006) Laser Doppler flowmetry detection of endothelial dysfunction in end-stage renal disease patients: correlation with cardiovascular risk. Kidney Int. 70, 157-164

22 Kubli, S., Waeber, B., Dalle-Ave, A. and Feihl, F. (2000) Reproducibility of laser-Doppler imaging of skin blood flow as a tool to assess endothelial function. J. Cardiovasc. Pharmacol. 36, 640-648

23 Golay, S., Haeberli, C., Delachaux, A., Liaudet, L., Kucera, P., Waeber, B. and Feihl, F. (2004) Local heating of human skin causes hyperemia without mediation by muscarinic cholinergic receptors or prostanoids. J. Appl. Physiol. 97, 1781-1786

24 Ciplak, M., Pasche, A., Heim, A., Haeberli, C., Waeber, B., Liaudet, L., Feihl, F. and Engelberger, R. (2009) The vasodilatory response of skin microcirculation to local heating is subject to desensitization. Microcirculation 16, 265-275

25 Taylor, W. F., Johnson, J. M., O’Leary, D. and Park, M. K. (1984) Effect of high local temperature on reflex cutaneous vasodilation. J. Appl. Physiol. 57, 191-196

26 Hand, M. F., Haynes, W. G. and Webb, D. J. (1998)

Hemodialysis and $\mathrm{L}$-arginine, but not $\mathrm{D}$-arginine, correct renal failure-associated endothelial dysfunction. Kidney Int. 53, 1068-1077

27 Kielstein, J. T., Boger, R. H., Bode-Boger, S. M., Schaffer, J., Barbey, M., Koch, K. M. and Frolich, J. C. (1999) Asymmetric dimethylarginine plasma concentrations differ in patients with end-stage renal disease: relationship to treatment method and atherosclerotic disease. J. Am. Soc. Nephrol. 10, 594-600

28 Hewitson, C. L., Whiting, M. J., Barbara, J. A. and Mangoni, A. A. (2007) Acute effects of haemodialysis on biochemical modulators of endothelial function. J. Intern. Med. 262, 571-580

29 Fleck, C., Janz, A., Schweitzer, F., Karge, E., Schwertfeger, M. and Stein, G. (2001) Serum concentrations of asymmetric (ADMA) and symmetric (SDMA) dimethylarginine in renal failure patients. Kidney Int. Suppl. 78, S14-S18

30 Fleck, C., Schweitzer, F., Karge, E., Busch, M. and Stein, G. (2003) Serum concentrations of asymmetric (ADMA) and symmetric (SDMA) dimethylarginine in patients with chronic kidney diseases. Clin. Chim. Acta 336, 1-12

31 da Silva, C. D., Brunini, T. M., Reis, P. F., Moss, M. B., Santos, S. F., Roberts, N. B., Ellory, J. C., Mann, G. E. and Mendes-Ribeiro, A. C. (2005) Effects of nutritional status on the L-arginine-nitric oxide pathway in platelets from hemodialysis patients. Kidney Int. 68, 2173-2179
32 Mochizuki, S., Ono, J., Yada, T., Ogasawara, Y., Miyasaka, T., Kimoto, M., Kashihara, N. and Kajiya, F. (2005) Systemic nitric oxide production rate during hemodialysis and its relationship with nitric oxide-related factors. Blood Purif. 23, 317-324

33 Reis, P. F., da Silva, C. D., Brunini, T. M., Moss, M. B., Siqueira, M. A., Santos, S. F., Roberts, N. B., Ellory, J. C., Mann, G. E. and Mendes-Ribeiro, A. C. (2006) Plasma amino acid profile and $\mathrm{L}$-arginine uptake in red blood cells from malnourished uremic patients. J. Renal Nutr. 16, 325-331

34 Baylis, C. (2008) Nitric oxide deficiency in chronic kidney disease. Am. J. Physiol. Renal Physiol. 294, F1-F9

35 Wahbi, N., Dalton, R. N., Turner, C., Denton, M., Abbs, I. and Swaminathan, R. (2001) Dimethylarginines in chronic renal failure. J. Clin. Pathol. 54, 470-473

36 Schiel, R., Franke, S., Busch, M., Muller, A., Fleck, C. Muller, U. A., Braun, A. and Stein, G. (2003) Effect of smoking on risk factors for cardiovascular disease in patients with diabetes mellitus and renal insufficiency. Eur. J. Med. Res. 8, 283-291

37 Martens-Lobenhoffer, J., Krug, O. and Bode-Boger, S. M. (2004) Determination of arginine and asymmetric dimethylarginine (ADMA) in human plasma by liquid chromatography/mass spectrometry with the isotope dilution technique. J. Mass Spectrom. 39, 1287-1294

38 Mendes Ribeiro, A. C., Roberts, N. B., Lane, C., Yaqoob, M. and Ellory, J. C. (1996) Accumulation of the endogenous L-arginine analogue $N^{G}$-monomethyl-Larginine in human end-stage renal failure patients on regular haemodialysis. Exp. Physiol. 81, 475-481

39 Kang, E. S., Tevlin, M. T., Wang, Y. B., Chiang, T. M., Cardenas, R., Myers, L. K. and Acchiardo, S. R. (1999) Hemodialysis hypotension: interaction of inhibitors, iNOS, and the interdialytic period. Am. J. Med. Sci. 317, 9-21

40 Bergamini, S., Vandelli, L., Bellei, E., Rota, C., Manfredini, P., Tomasi, A., Albertazzi, A. and Iannone, A. (2004) Relationship of asymmetric dimethylarginine to haemodialysis hypotension. Nitric Oxide 11, 273-278

41 Kalousova, M., Kielstein, J. T., Hodkova, M., Zima, T., Dusilova-Sulkova, S., Martens-Lobenhoffer, J. and Bode-Boger, S. M. (2006) No benefit of hemodiafiltration over hemodialysis in lowering elevated levels of asymmetric dimethylarginine in ESRD patients. Blood Purif. 24, 439-444

42 Bode-Boger, S. M., Scalera, F. and Ignarro, L. J. (2007) The L-arginine paradox: importance of the $\mathrm{L}$-arginine/ asymmetrical dimethylarginine ratio. Pharmacol. Ther. 114, 295-306

43 Kielstein, J. T., Boger, R. H., Bode-Boger, S. M., Martens-Lobenhoffer, J., Lonnemann, G., Frolich, J. C., Haller, H. and Fliser, D. (2004) Low dialysance of asymmetric dimethylarginine (ADMA): in vivo and in vitro evidence of significant protein binding. Clin. Nephrol. 62, 295-300

44 Billecke, S. S., Kitzmiller, L. A., Northrup, J. J., Whitesall, S. E., Kimoto, M., Hinz, A. V. and D’Alecy, L. G. (2006) Contribution of whole blood to the control of plasma asymmetrical dimethylarginine. Am. J. Physiol. Heart Circ. Physiol. 291, H1788-H1796

45 Cardounel, A. J., Cui, H., Samouilov, A., Johnson, W. Kearns, P., Tsai, A. L., Berka, V. and Zweier, J. L. (2007) Evidence for the pathophysiological role of endogenous methylarginines in regulation of endothelial $\mathrm{NO}$ production and vascular function. J. Biol. Chem. 282, 879-887

46 Stewart, J., Kohen, A., Brouder, D., Rahim, F., Adler, S., Garrick, R. and Goligorsky, M. S. (2004) Noninvasive interrogation of microvasculature for signs of endothelial dysfunction in patients with chronic renal failure. Am. J. Physiol. Heart Circ. Physiol. 287, H2687-H2696

47 Noon, J. P., Walker, B. R., Webb, D. J., Shore, A. C., Holton, D. W., Edwards, H. V. and Watt, G. C. (1997) Impaired microvascular dilatation and capillary rarefaction in young adults with a predisposition to high blood pressure. J. Clin. Invest. 99, 1873-1879

48 Feihl, F., Liaudet, L., Waeber, B. and Levy, B. I. (2006) Hypertension, a disease of the microcirculation? Hypertension 48, 1012-1017 
49 Cooke, J. P. (2003) NO and angiogenesis. Atheroscler. Suppl. 4, 53-60

50 O'Riordan, E., Mendelev, N., Patschan, S., Patschan, D., Eskander, J., Cohen-Gould, L., Chander, P. and Goligorsky, M. S. (2007) Chronic NOS inhibition actuates endothelial-mesenchymal transformation. Am. J. Physiol. Heart Circ. Physiol. 292, H285-H294

51 Kosch, M., Levers, A., Barenbrock, M., Matzkies, F., Schaefer, R. M., Kisters, K., Rahn, K. H. and Hausberg, M. (2001) Acute effects of haemodialysis on endothelial function and large artery elasticity. Nephrol. Dial. Transplant. 16, 1663-1668

52 Cupisti, A., Rossi, M., Placidi, S., Caprioli, R., Morelli, E., Vagheggini, G. and Barsotti, G. (2000) Responses of the skin microcirculation to acetylcholine and to sodium nitroprusside in chronic uremic patients. Int. J. Clin. Lab. Res, 30, 157-162

53 Miyazaki, H., Matsuoka, H., Itabe, H., Usui, M., Ueda, S., Okuda, S. and Imaizumi, T. (2000) Hemodialysis impairs endothelial function via oxidative stress: effects of vitamin E-coated dialyzer. Circulation 101, 1002-1006

54 Lilien, M. R., Koomans, H. A. and Schroder, C. H. (2005) Hemodialysis acutely impairs endothelial function in children. Pediatr. Nephrol. 20, 200-204

55 Kosch, M., Levers, A., Fobker, M., Barenbrock, M., Schaefer, R. M., Rahn, K. H. and Hausberg, M. (2003) Dialysis filter type determines the acute effect of haemodialysis on endothelial function and oxidative stress. Nephrol. Dial. Transplant. 18, 1370-1375

56 Cross, J. M., Donald, A., Vallance, P. J., Deanfield, J. E., Woolfson, R. G. and MacAllister, R. J. (2001) Dialysis improves endothelial function in humans. Nephrol. Dial. Transplant. 16, 1823-1829

57 McGregor, D. O., Buttimore, A. L., Lynn, K. L., Yandle, T. and Nicholls, M. G. (2003) Effects of long and short hemodialysis on endothelial function: a short-term study. Kidney Int. 63, 709-715

58 Chan, C. T., Harvey, P. J., Boger, R., Pierratos, A. and Floras, J. S. (2005) Dissociation between the short-term effects of nocturnal hemodialysis on endothelium dependent vasodilation and plasma ADMA. Arterioscler. Thromb. Vasc. Biol. 25, 2685-2686
59 Mittermayer, F., Schaller, G., Pleiner, J., Vychytil, A., Sunder-Plassmann, G., Horl, W. H. and Wolzt, M. (2005) Asymmetrical dimethylarginine plasma concentrations are related to basal nitric oxide release but not endotheliumdependent vasodilation of resistance arteries in peritoneal dialysis patients. J. Am. Soc. Nephrol. 16, 1832-1838

60 Yilmaz, M. I., Saglam, M., Caglar, K., Cakir, E., Ozgurtas, T., Sonmez, A., Eyileten, T., Yenicesu, M., Acikel, C., Oguz, Y. et al. (2005) Endothelial functions improve with decrease in asymmetric dimethylarginine (ADMA) levels after renal transplantation. Transplantation 80, 1660-1666

61 Cross, J. M., Donald, A. E., Kharbanda, R., Deanfield, J. E., Woolfson, R. G. and MacAllister, R. J. (2001) Acute administration of $\mathrm{L}$-arginine does not improve arterial endothelial function in chronic renal failure. Kidney Int. 60, 2318-2323

62 Kielstein, J. T. and Zoccali, C. (2005) Asymmetric dimethylarginine: a cardiovascular risk factor and a uremic toxin coming of age? Am. J. Kidney Dis. 46, 186-202

63 Linden, E., Cai, W., He, J. C., Xue, C., Li, Z., Winston, J., Vlassara, H. and Uribarri, J. (2008) Endothelial dysfunction in patients with chronic kidney disease results from advanced glycation end products (AGE)-mediated inhibition of endothelial nitric oxide synthase through RAGE activation. Clin. J. Am. Soc. Nephrol. 3, 691-698

64 van der Sande, F. M., Rosales, L. M., Brener, Z., Kooman, J. P., Kuhlmann, M., Handelman, G., Greenwood, R. N., Carter, M., Schneditz, D., Leunissen, K. M. and Levin, N. W. (2005) Effect of ultrafiltration on thermal variables, skin temperature, skin blood flow, and energy expenditure during ultrapure hemodialysis. J. Am. Soc. Nephrol. 16, 1824-1831

65 Kellogg, Jr, D. L. (2006) In vivo mechanisms of cutaneous vasodilation and vasoconstriction in humans during thermoregulatory challenges. J. Appl. Physiol. 100, 1709-1718

66 Vij, R. S., Motiwala, S. and Peixoto, A. J. (2008) Reproducibility of systemic hemodynamics in stable chronic hemodialysis: a pilot study. Blood Pressure Monit. 13, 291-294

67 Daugirdas, J. T. (1993) Second generation logarithmic estimates of single-pool variable volume $\mathrm{Kt} / \mathrm{V}$ : an analysis of error. J. Am. Soc. Nephrol. 4, 1205-1213 